\title{
Solid-Contact Potentiometric Anion Sensing Based on Classic Silver/Silver Insoluble Salts Electrodes without Ion-Selective Membrane
}

\author{
Chunxian Liao ${ }^{1}$, Lijie Zhong ${ }^{1}$, Yitian Tang ${ }^{1,2}$, Zhonghui Sun ${ }^{1}$, Kanglong Lin ${ }^{1}$, Longbin Xu ${ }^{1,2}$, Yan Lyu ${ }^{1,2}$, \\ Dequan $\mathrm{He}^{1}$, Ying $\mathrm{He}^{1}$, Yingming Ma ${ }^{1}$, Yu Bao ${ }^{1}$, Shiyu Gan ${ }^{1, * \mathbb{D}}$ and Li Niu ${ }^{1}(\mathbb{D}$
}

1 Guangzhou Key Laboratory of Sensing Materials \& Devices, Center for Advanced Analytical Science, School of Chemistry and Chemical Engineering, Guangzhou University, Guangzhou 510006, China; gdcxliao@e.gzhu.edu.cn (C.L.); ccljzhong@gzhu.edu.cn (L.Z.); yitiantang@e.gzhu.edu.cn (Y.T.); cczhsun@gzhu.edu.cn (Z.S.); longkanglin@e.gzhu.edu.cn (K.L.); longbinx@gzhu.edu.cn (L.X.); yanlyu@e.gzhu.edu.cn (Y.L.); dequanhe@e.gzhu.edu.cn (D.H.); ccyhe@gzhu.edu.cn (Y.H.); ccymma@gzhu.edu.cn (Y.M.); baoyu@gzhu.edu.cn (Y.B.); lniu@gzhu.edu.cn (L.N.)

2 School of Civil Engineering, Guangzhou University, Guangzhou 510006, China

* Correspondence: ccsygan@gzhu.edu.cn

\section{check for} updates

Citation: Liao, C.; Zhong, L.; Tang, Y.; Sun, Z.; Lin, K.; Xu, L.; Lyu, Y.; He, D.; He, Y.; Ma, Y.; et al. Solid-Contact Potentiometric Anion Sensing Based on Classic Silver/Silver Insoluble Salts Electrodes without Ion-Selective Membrane. Membranes 2021, 11, 959. https://doi.org/10.3390/

membranes11120959

Academic Editor:

Beata Paczosa-Bator

Received: 4 November 2021

Accepted: 28 November 2021

Published: 5 December 2021

Publisher's Note: MDPI stays neutral with regard to jurisdictional claims in published maps and institutional affiliations.

Copyright: (c) 2021 by the authors. Licensee MDPI, Basel, Switzerland. This article is an open access article distributed under the terms and conditions of the Creative Commons Attribution (CC BY) license (https:/ / creativecommons.org/licenses/by/ $4.0 /)$.

\begin{abstract}
Current solid potentiometric ion sensors mostly rely on polymeric-membrane-based, solidcontact, ion-selective electrodes (SC-ISEs). However, anion sensing has been a challenge with respect to cations due to the rareness of anion ionophores. Classic metal/metal insoluble salt electrodes (such as $\mathrm{Ag} / \mathrm{AgCl}$ ) without an ion-selective membrane (ISM) offer an alternative. In this work, we first compared the two types of SC-ISEs of $\mathrm{Cl}^{-}$with/without the ISM. It is found that the ISMfree $\mathrm{Ag} / \mathrm{AgCl}$ electrode discloses a comparable selectivity regarding organic chloride ionophores. Additionally, the electrode exhibits better comprehensive performances (stability, reproducibility, and anti-interference ability) than the ISM-based SC-ISE. In addition to $\mathrm{Cl}^{-}$, other $\mathrm{Ag} / \mathrm{AgX}$ electrodes also work toward single and multi-valent anions sensing. Finally, a flexible $\mathrm{Cl}^{-}$sensor was fabricated for on-body monitoring the concentration of sweat $\mathrm{Cl}^{-}$to illustrate a proof-of-concept application in wearable anion sensors. This work re-emphasizes the ISM-free SC-ISEs for solid anion sensing.
\end{abstract}

Keywords: potentiometric sensing; anion sensors; ion-selective electrodes; wearable ion sensors

\section{Introduction}

On-site ion analysis and monitoring in complex environments require miniaturized and integrated devices. The representative electrochemical ion analytical methods are focused on ion-selective electrodes (ISEs) [1] and ion transfer at the interface between immiscible electrolyte solutions (ITIES) [2]. The classic ISEs are the liquid-junction system, which is limited to miniaturization due to an inner filling solution. ITIES electrochemistry can be used for an ion-sensing platform by tuning an externally applied potential. Either option faces the possibility of miniaturization and integration. Solid-contact ion-selective electrodes (SC-ISEs) are developed from the classic liquid-junction ISEs, which satisfy the requirement of on-site ion analysis [3-7]. Since the concept of SC-ISEs [8] was first proposed in 1971, this solid-state potentiometric sensing has been expanded from detection of ions to molecules [9,10], biomolecules [11-14], and even bacteria [15,16]. The basic structure is composed of a sandwich model, including two layers of solid contact (ion-toelectron signal transduction) and ion-selective membrane (ISM, ion recognition). There are two long-lasting challenges to this structure. One is the potential stability and/or reproducibility caused by the ultrathin water layer and interfacial capacitance between solid contact and ISM [17-20]. Numerous efforts have been devoted to improving the properties of SC materials (such as hydrophobicity and redox capacitance with defined phase boundary potential) to address these issues [19-25]. The other is the leaking of 
ISM components leading to biological toxicity [26], particularly for medical applications. In addition, the weak mechanical strength of the organic ISM results in a short life in a complex environment.

Currently, most of SC-ISEs have focused on the detection of cations, while there are only a few reports for anion sensing. The early reported anion SC-ISEs are based on plastic ion exchangers without ionophores [27-34]. For example, poly (vinyl chloride)-matrix (PVC) membrane containing chlorate ion exchanger was proposed for solid-state chlorate ISE [27]. Since the ISM was prepared through ion exchange (such as a nitrate ion exchanger), the selectivity ability toward interfering nitrate is rather low. Later, ionophorebased anion SC-ISEs have been developed [35-40]. For example, 4-(4-bromophenyl)-2,6diphenylpyrilium perchlorate (BDPP) was synthesized for solid-state sulfate sensing [35], which exhibits improved selectivity and a low detection limit. Recently, multiwalled carbon nanotube as the SC layer coupled with anion-selective ionophores has realized sensing toward a few anions in seawater [39]. To regulate the selectivity and sensitivity, porphyrin dimers through molecular bridge connection have been recently proposed as promising anion/cation acceptors (such as $\mathrm{ClO}_{4}^{-}$) compared to a traditional single porphyrin unit [40]. Another classic potentiometric anion sensor is based on metal/metal insoluble salts electrodes without ISM, typically like the $\mathrm{Ag} / \mathrm{AgCl}$ electrode for $\mathrm{Cl}^{-}$sensing [41-46]. It relies on an equilibrium between $\mathrm{AgCl}$ and $\mathrm{Cl}^{-}\left(\mathrm{AgCl}(\mathrm{s})+\mathrm{e}^{-} \leftrightarrow \mathrm{Cl}^{-}\right.$(aq) $\left.+\mathrm{Ag}(\mathrm{s})\right)$. The unique lattice of silver chloride makes $\mathrm{Cl}^{-}$exchange between solid $\mathrm{AgCl}$ and the solution, which is the origin of a specific response to $\mathrm{Cl}^{-}$. The $\mathrm{Ag} / \mathrm{AgCl}$ electrode has been used for environmental $\mathrm{Cl}^{-}$detection, for example, by using a screen-printed technique [43]. Other metal/metal insoluble salts electrodes, typically like $\mathrm{Ag} / \mathrm{Ag}_{2} \mathrm{~S}$ [47] and $\mathrm{Pb} / \mathrm{PbSiO}_{3}$ [48] without ISM, have been demonstrated for sensing toward $\mathrm{S}^{2-}$ and silicate, respectively. Early studies indicate the possibility of constructing the ISM-free SC-ISEs. Recently, we presented a new type of SC-ISEs without using the ISM based on classic Li-ion battery materials [49]. The materials (such as $\mathrm{LiFePO}_{4}$ and $\mathrm{LiMn}_{2} \mathrm{O}_{4}$ ) as solid contact layers can realize both functions of ion-to-electron transduction and ion recognition.

In this work, we first compare two types of SC-ISEs of $\mathrm{Cl}^{-}$with ISM and without ISM. It is found that the ISM-free $\mathrm{Ag} / \mathrm{AgCl}$ electrode discloses a comparable selectivity regarding ISM-based SC-ISE of $\mathrm{Cl}^{-}$, and much better performances of response time, stability, reproducibility, and anti-interferences from gas and light. More importantly, these silver/silver insoluble salts electrodes are also feasible for other single and multi-valent anions sensing. Moreover, a wearable $\mathrm{Cl}^{-}$sensor based on the $\mathrm{Ag} / \mathrm{AgCl}$ electrode was fabricated. The electrode maintained mechanical flexibility and analytical performances under the bending state. The sweat $\mathrm{Cl}^{-}$concentration was monitored by a flexible wearable sensor. Through this work, we re-emphasize the ISM-free SC-ISEs for solid anion sensing.

\section{Materials and Methods}

\subsection{Reagents}

Potassium tetrakis(pentafluorophenyl)borate (KTPFB, 97\%) was purchased from Alfa (Shanghai, China). High-molecular-weight poly(vinyl chloride) (PVC) (Selectophore), tridodecylmethylammonium chloride (TDMACl, 98\%), Bis(2-ethylhexyl) sebacate (DOS, $\geq 97 \%$ ), Chloride ionophore I (Selectophore), and tetrahydrofuran (THF) (anhydrous, $\geq 99 \%$, inhibitorfree) were obtained from Sigma-Aldrich (Shanghai, China). All the reagents were used directly after receiving, and then using ultrapure water $(18.2 \mathrm{M} \Omega \cdot \mathrm{cm})$ to prepare aqueous solutions.

\subsection{Preparation of Electrodes}

The silver electrodes with a diameter of $3 \mathrm{~mm}$ were polished with $1 \mu \mathrm{m}$ and $0.3 \mu \mathrm{m}$ alumina powder, then were ultrasonically and successively cleaned with water-ethanolwater. The silver electrode was then placed in $3 \mathrm{M} \mathrm{KCl}$ aqueous solution and deposited with a thin layer of gray-black silver chloride in a constant current of $25 \mu \mathrm{A}$ for $90 \mathrm{~min}$. This was the preparation procedure for the $\mathrm{Ag} / \mathrm{AgCl}$ electrode. The ISM electrode was 
obtained by dropping $20 \mu \mathrm{L} \mathrm{Cl}^{-}$selective membrane solution onto the $\mathrm{Ag} / \mathrm{AgCl}$ electrode. The $\mathrm{Cl}^{-}$selective membrane solution was obtained by dissolving $250 \mathrm{mg}$ of the membrane cocktail in $2.5 \mathrm{~mL}$ of THF: $32.9 \mathrm{wt} \%$ PVC and $65.7 \mathrm{wt} \%$ DOS, $1 \mathrm{wt} \%$ Chloride ionophore $\mathrm{I}$, and $0.4 \mathrm{wt} \% \mathrm{TDMACl}$. The membrane solution was stored at $4{ }^{\circ} \mathrm{C}$. Before the test, the $\mathrm{Ag} / \mathrm{AgCl}$ electrode without ISM was conditioned in a $10^{-7} \mathrm{M} \mathrm{KCl}$ aqueous solution for $2 \mathrm{~h}$. The ISM electrode was firstly balanced in $10^{-4} \mathrm{M} \mathrm{KCl}$ aqueous solution overnight, and then conditioned in a $10^{-7} \mathrm{M} \mathrm{KCl}$ aqueous solution for $3 \mathrm{~h}$ before the test.

\subsection{Preparation of Flexible Electrodes}

A poly(ethylene terephthalate) (PET) substrate of $7 \times 7 \mathrm{~cm}^{2}$ was cleaned successively with water-acetone-isopropanol, and then was etched with $\mathrm{O}_{2}$ plasma for $2 \mathrm{~min}$. Then, the PET substrate was sputtered with 30-40-200 nm chrome-gold-silver electrode ( $5 \mathrm{~mm}$ diameter) by using ultra-high vacuum sputtering technology (AJA Orion 5, Scituate, MA, USA). After coating with a polydimethylsiloxane (PDMS) insulating layer, the flexible electrode was dried at $90^{\circ} \mathrm{C}$ for $50 \mathrm{~min}$. The flexible $\mathrm{Ag} / \mathrm{AgCl}$ electrode was obtained by oxidizing the silver electrode in $0.05 \mathrm{M} \mathrm{FeCl}_{3}$ for $10 \mathrm{~s}$. For the preparation of the all-solidstate reference electrode (RE), the PET-supported chrome-gold-silver electrode was first oxidized in $0.05 \mathrm{M} \mathrm{FeCl}_{3}$ for $10 \mathrm{~s}$ to form $\mathrm{Ag} / \mathrm{AgCl}$. Then, $20 \mu \mathrm{L}$ reference membrane (RM) solution was drop-casted on the $\mathrm{Ag} / \mathrm{AgCl}$ and dried overnight in ambient conditions. The RM solution was prepared by dissolving $500 \mathrm{mg}$ of the membrane cocktail in $5 \mathrm{~mL}$ of THF: $150 \mathrm{mg}$ PVC and $340 \mathrm{mg}$ DOS, $5.5 \mathrm{mg}$ TDMACl, $4.5 \mathrm{mg} \mathrm{KTPFB}, 808 \mathrm{mg} \mathrm{KCl}$, and $306 \mathrm{mg}$ $\mathrm{AgCl}$ powder were mixed and stirred overnight at ambient temperature [50,51]. After the RM dried, a reference protection layer was further covered on the RM. The protection layer was prepared by dissolving $80 \mathrm{mg}$ of the cocktail in $1 \mathrm{~mL}$ of THF: $26.48 \mathrm{mg}$ PVC and $53.52 \mathrm{mg}$ DOS. After coating, the electrode was dried at ambient temperature overnight. The principle for the all-solid-state RE is the same as the liquid-junction RE but with a solid electrolyte membrane instead. Before the test, the flexible $\mathrm{Ag} / \mathrm{AgCl}$ electrode was conditioned in $10^{-7} \mathrm{M} \mathrm{KCl}$ aqueous solution for $2 \mathrm{~h}$, while the RE was balanced in $3 \mathrm{M}$ $\mathrm{KCl}$ aqueous solution overnight.

\subsection{Electrochemical Characterization of SC-ISEs}

All electrochemical performances of the electrodes were characterized by a Gamry electrochemical workstation (reference 600 plus, Gamry, Warminster, PA, USA) and multichannel potentiometer EMF6 (Lawson Lab, Inc., Malvern, PA, USA) at ambient conditions. The on-body sweat analysis was carried out by a home-made mini-potentiometer with an input resistance of $10^{13} \Omega$. The electrode concentration-response curves (including determination of selectivity coefficient) were measured in the aqueous solutions $\left(10^{-7} \mathrm{M}\right.$ to $\left.10^{-1} \mathrm{M}\right)$, and the Debye-Hückel equation was used to correct the ion activities. Other performance characterizations were performed, including chronopotentiometry $( \pm 1 \mathrm{nA}$ current applied), water layer, and anti-interference experiments. A commercial $\mathrm{Hg} / \mathrm{Hg}_{2} \mathrm{Cl}_{2}$ /saturated $\mathrm{KCl} / 1 \mathrm{M}$ LiOAc (Tjaida, Tianjing, China) was used as a reference electrode, and a platinum wire was used as the auxiliary electrode.

\subsection{Sweat Analysis}

A commercial sweat guide band was used to fix the prepared flexible electrode and to enrich the sweat. Combining with a multi-channel mini-potentiometer (home-made) and wireless data transmission mode, the chloride ion concentration in the sweat produced by the volunteer during running was analyzed. Before starting the run, the volunteer's forehead was wiped with medical alcohol and deionized water in turn. Then, the volunteer ran at a graded load on the treadmill for a period and used a microtubule to collect the sweat sample after cooling down. After the concentration of $\mathrm{Cl}^{-}$in sweat was in situ analyzed by using the flexible wearable $\mathrm{Ag} / \mathrm{AgCl}$ electrode, the sweat sample was diluted and analyzed with an ion chromatograph. It should be noted that the volunteer agrees to this test of wearable sensors for sweat analysis. 


\section{Results and Discussion}

\subsection{Potentiometric Responses of SC-ISEs of $\mathrm{Cl}^{-}$with/without ISM}

Two types of typical SC-ISEs $\left(\mathrm{Cl}^{-}\right)$are shown in Figure 1a,b. One is the threelayer structure based on an ISM containing chloride ionophore I (Figure 1a). It should be noted that the solid contacts could be other materials, such as the classic poly $(3,4-$ ethylenedioxythiophene) (PEDOT) or carbon-based materials. Herein, the Ag/ AgCl was chosen as the SC layer for a direct comparison. The other is bare $\mathrm{Ag} / \mathrm{AgCl}$ without ISM (Figure 1b). We first compare the potentiometric responses of the ISM electrode and $\mathrm{Ag} / \mathrm{AgCl}$ electrode toward $\mathrm{Cl}^{-}$. The potential response curves of both electrodes were measured in $\mathrm{KCl}$ solution (range from $10^{-7}$ to $10^{-1} \mathrm{M}$ ) with three separately prepared electrodes. As shown in Figure 1c, the ISM electrode shows a response starting from $\sim 10^{-5} \mathrm{M}$ with a response time around $94 \mathrm{~s}$ (the inset). This slow potential equilibrium limits the application in rapid on-site detection. Its calibration curve exhibits the sensitivity of $-61.7 \pm 2.4 \mathrm{mV} \mathrm{dec}^{-1}$ and standard $\mathrm{E}^{0}$ of $-32.3 \pm 5.9 \mathrm{mV}$ within the linear response range $\sim 10^{-5}$ to $10^{-1} \mathrm{M}$ (Figure 1d). The limit of detection (LOD) of ISM electrode for $\mathrm{Cl}^{-}$is $1.08 \times 10^{-5} \mathrm{M}$. For comparison, the ISM-free $\mathrm{Ag} / \mathrm{AgCl}$ electrode exhibits a similar potentiometric response toward $\mathrm{Cl}^{-}$(Figure 1e) with a Nernst slope of $-57.1 \pm 1.2 \mathrm{mV}$ $\mathrm{dec}^{-1}$ and a close LOD of $1.47 \times 10^{-5} \mathrm{M}$ (Figure 1f). The response time for $\mathrm{Ag} / \mathrm{AgCl}$ of $\sim 25 \mathrm{~s}$ (the inset, Figure 1e) is much faster than the ISM electrode. It should be noted that the response time is defined at the electromotive force (EMF) with a difference of $0.5 \mathrm{mV}$ from the final steady EMF. In addition, the $\mathrm{E}^{0}$ of $-14.1 \pm 2.6 \mathrm{mV}$ showed a lesser standard deviation (Figure 1f), which indicates a better reproducibility.

In addition to the target ion response, another crucial parameter for SC-ISEs is the selectivity toward interfering ions. The separation solution method was used to determine the selectivity toward other anions for both electrodes. Taking interfering anion $\mathrm{NO}_{3}{ }^{-}$ as an example, the potential response curves of $\mathrm{Ag} / \mathrm{AgCl}$ and ISM electrodes to nitrate ion were measured in $\mathrm{KNO}_{3}$ solution with concentrations ranging from $10^{-7}$ to $10^{-1} \mathrm{M}$ (Figure $1 \mathrm{~g}$ ). It was found that the $\mathrm{Ag} / \mathrm{AgCl}$ electrode had almost no response during the whole concentration range (blue line, Figure $1 \mathrm{~g}$ ), while the ISM electrode disclosed a Nernst response toward $\mathrm{NO}_{3}{ }^{-}$(orange line, Figure 1g). Through calculation, the selectivity coefficients $\left(\log \mathrm{K}_{\mathrm{ij}}\right)$ toward $\mathrm{NO}_{3}{ }^{-}$were determined to be $-3.53 \pm 0.03$ for $\mathrm{Ag} / \mathrm{AgCl}$ and $-0.49 \pm 0.19$ for the ISM electrode. The selectivity improved for nearly three orders of magnitudes. Other interfering ion measurements are shown in Figure S1. All selectivity coefficients are summarized in Figure 1h. It was surprisingly found that the selectivity of the $\mathrm{Ag} / \mathrm{AgCl}$ electrode to $\mathrm{Cl}^{-}$is much better than that of the ISM electrode. Except for $\mathrm{PO}_{4}{ }^{3-}$, the selectivity toward other interfering ions is at least one magnitude higher than the organic chloride ionophore I.

It should be noted that chloride ionophore I was chosen as the ionic carrier due to it being a commercial chemical and having a relatively low cost. We also compared the selectivity of $\mathrm{Ag} / \mathrm{AgCl}$ with a representative lab-synthesized anion receptor, 2-(1-H-imidazo [4,5-f] [1,10]-phenanthroline-2-yl)-6methoxyphenol (HIPM) [52]. The HIPM shows the log $K_{\mathrm{ij}}=-4.54\left(\mathrm{NO}_{3}{ }^{-}\right),-3.08\left(\mathrm{HCO}_{3}{ }^{-}\right),-4.27\left(\mathrm{SO}_{4}{ }^{2-}\right)$, and $-4.53\left(\mathrm{HPO}_{4}{ }^{2-}\right)$ (Figure 1h). Regarding HIPM, Ag/ $\mathrm{AgCl}$ exhibits relatively less selectivity toward $\mathrm{NO}_{3}{ }^{-}$but comparable selective abilities toward other anions. We also compared the analytical performances of $\mathrm{Ag} / \mathrm{AgCl}$ electrodes with previously reported SC-ISEs of $\mathrm{Cl}^{-}$sensors (Tables S1 and S2, Supporting Information). It is found that the as-prepared ISM-free Ag/ $\mathrm{AgCl}$ discloses comparable or even better comprehensive performances compared with/without ISM-based $\mathrm{Cl}^{-}$sensors. Overall, the above results demonstrated the Nernst response, rapid response time, good selectivity, and reproducibility for the ISM-free Ag/AgCl. Other important electrochemical performances are further evaluated, including stability and anti-light and gas abilities. 
a SC-ISES (Cl) with ISM

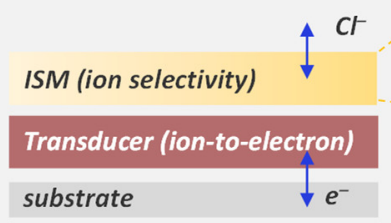

C

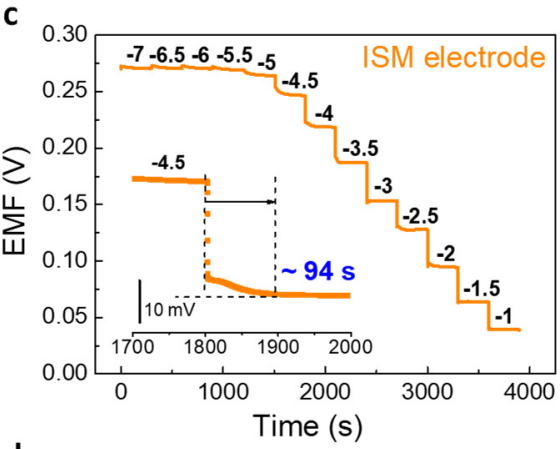

d

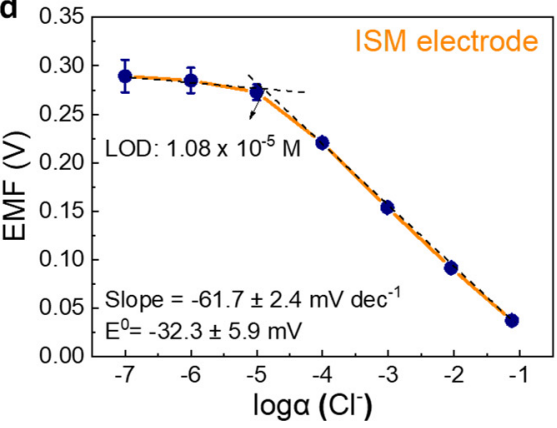

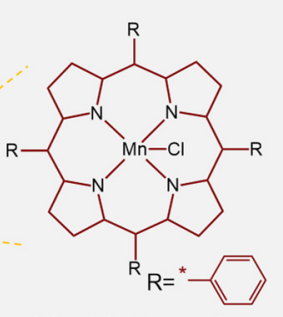

Chloride ionophore I b SC-ISES $\left(\mathrm{Cl}^{-}\right)$without ISM

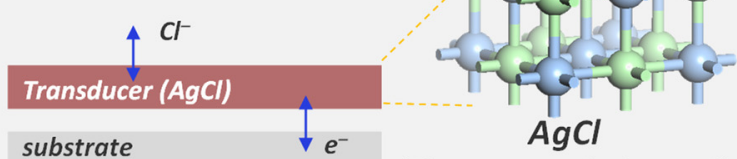

(Cl- recognition by lattice $\mathrm{Cl}$ )

g

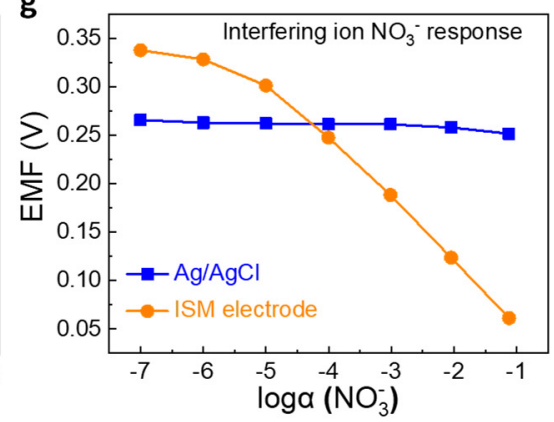

h

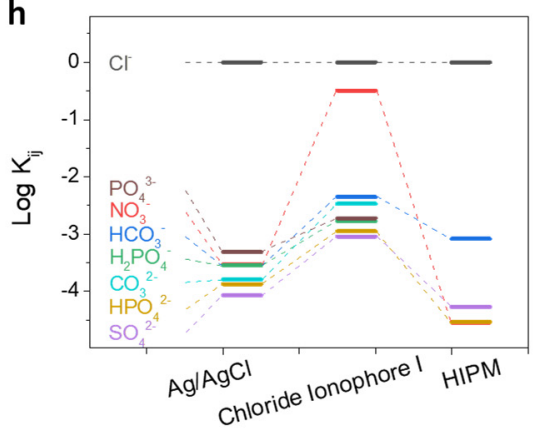

Figure 1. Potentiometric responses of ion-selective membrane (ISM) electrode and $\mathrm{Ag} / \mathrm{AgCl}$ electrode toward $\mathrm{Cl}^{-}$. (a,b) $\mathrm{A}$ schematic diagram illustrates two types of solid-contact ion-selective electrodes (SC-ISEs) of $\mathrm{Cl}^{-}$including (a) ISM-based sandwich structure supported by $\mathrm{Ag} / \mathrm{AgCl}$ solid contact and (b) ISM-free structure of bare $\mathrm{Ag} / \mathrm{AgCl}$. Chloride ionophore I was used for $\mathrm{Cl}^{-}$recognition in ISM. (c,d) Potentiometric response and calibration curve of the ISM electrode from $0.1 \mu \mathrm{M}$ to $0.1 \mathrm{M} \mathrm{Cl}^{-}$. The inset shows the response time. It should be noted that the response time is defined at the electromotive force (EMF) with a difference of $0.5 \mathrm{mV}$ from the final steady EMF. (e,f) Potentiometric response and calibration curve of the $\mathrm{Ag} / \mathrm{AgCl}$ from $0.1 \mu \mathrm{M}$ to $0.1 \mathrm{M} \mathrm{Cl}^{-}$. The inset shows the response time. (g) Potentiometric responses of ISM electrode and $\mathrm{Ag} / \mathrm{AgCl}$ toward an example of interfering ion $\mathrm{NO}_{3}{ }^{-}$. (h) Comparison of selectivity coefficients towards a series of interfering ions. The coefficients were measured by the separation solution method. All the error bars shown in the figures indicate three individual electrodes. The data for the $\mathrm{Cl}^{-}$receptor of 2- (1-H-imidazo [4,5-f] [1,10]-phenanthroline-2-yl) -6 methoxyphenol (HIPM) is adapted from reference [52].

\subsection{Comparison of Stability and Anti-Interference}

Another crucial basis for the SC-ISEs is the potential stability. A short-term potential stability of the electrodes was first evaluated using reversed-current chronopotentiometry. According to the typical chronopotentiogram in Figure $2 \mathrm{a}$, when the currents of +1 and -1 $\mathrm{nA}$ were applied to the two electrodes for $100 \mathrm{~s}$, the potential change of the ISM electrode $\left(14.67 \mu \mathrm{V} \mathrm{s}^{-1}\right)$ was significantly greater than that of the $\mathrm{Ag} / \mathrm{AgCl}$ electrode $\left(0.31 \mu \mathrm{V} \mathrm{s}^{-1}\right)$. The interfacial capacitances can be calculated according to the equation $\Delta \mathrm{E} / \Delta \mathrm{t}=i / \mathrm{C}$. The $\mathrm{Ag} / \mathrm{AgCl}$ and ISM electrodes show the capacitances of $3.22 \mathrm{mF}$ and $0.068 \mathrm{mF}$, respectively. Obviously, the $\mathrm{Ag} / \mathrm{AgCl}$ exhibits 50-folders higher capacitance so that a lower potential drift resulted compared with the ISM electrode. Another possible reason for the potential drift of the ISM electrode was the introduction of a layer of ISM, leading to the formation 
of a water layer at the SC/ISM interface. To examine this effect, the water layer tests are further performed.
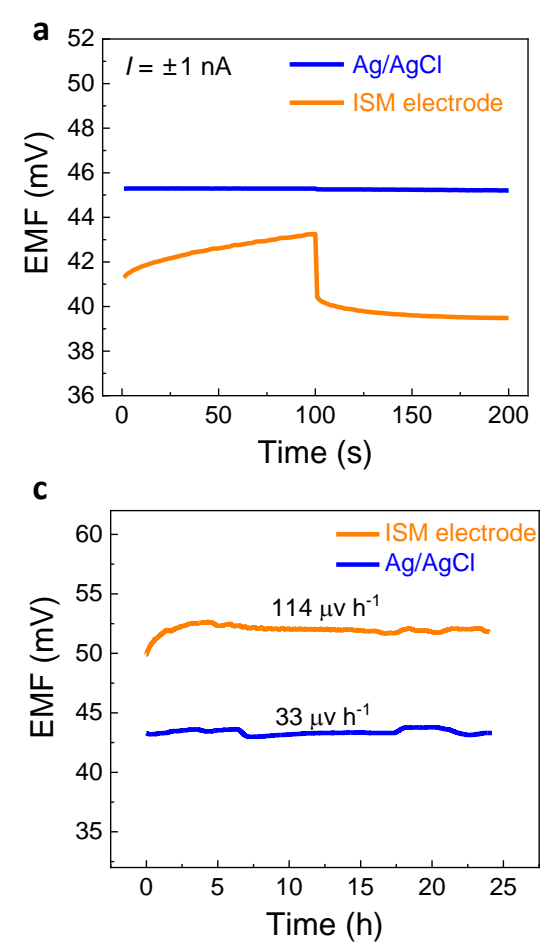

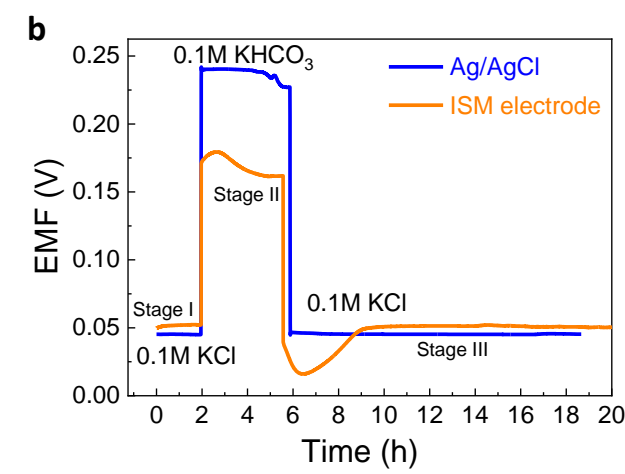

d

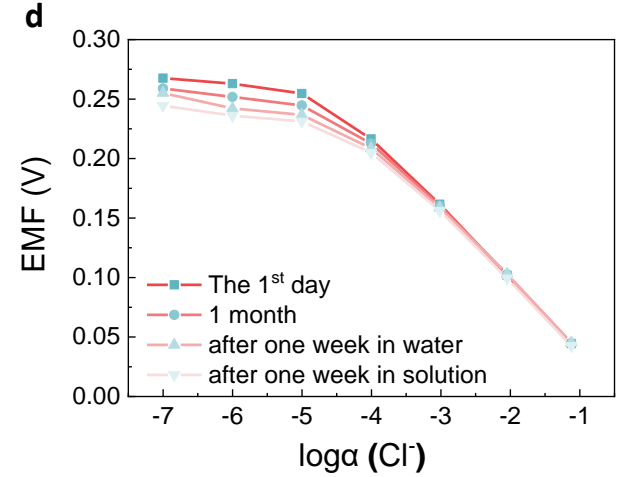

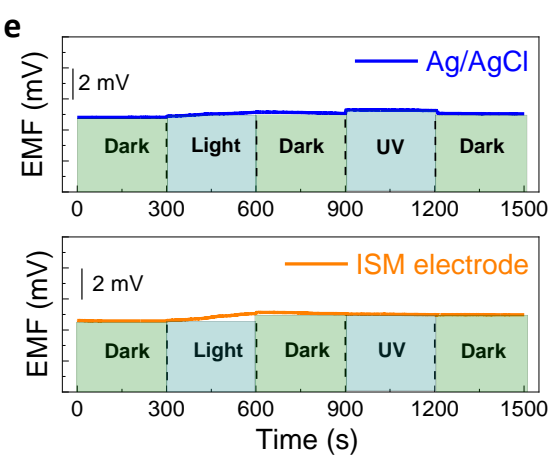

f
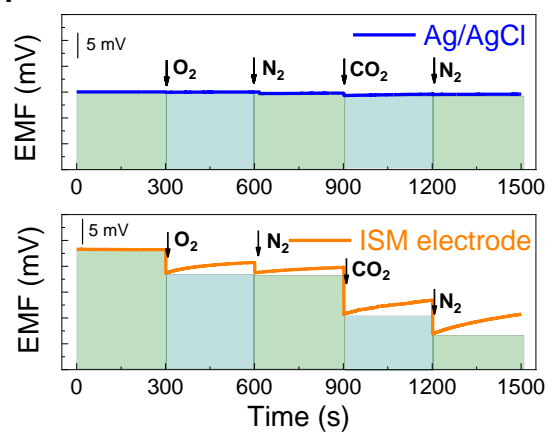

Figure 2. Stability and anti-interference of $\mathrm{Ag} / \mathrm{AgCl}$ electrode and ISM electrode. (a) Chronopotentiometry measurements in $0.1 \mathrm{M} \mathrm{KCl}$ at the current $(I)$ of $\pm 1 \mathrm{nA}$. (b) Water-layer tests for both electrodes. (c) Medium-term stability of the $\mathrm{Ag} / \mathrm{AgCl}$ electrode and the ISM electrode in $0.1 \mathrm{M} \mathrm{KCl}$. (d) Long-term stability of the $\mathrm{Ag} / \mathrm{AgCl}$ electrode under different storage conditions. (e,f) Light- and gas-sensitive examinations.

The potentiometric test for the water-layer examination was firstly measured in $0.1 \mathrm{M}$ $\mathrm{KCl}$, then in $0.1 \mathrm{M} \mathrm{KHCO}_{3}$, and again back in $0.1 \mathrm{M} \mathrm{KCl}$ (Figure 2b). The ISM electrode reveals a significant potential drift, particularly at stage II, i.e., upon transferring from $\mathrm{KCl}$ to interfering ion solution $\left(\mathrm{KHCO}_{3}\right)$ (orange line, Figure $2 \mathrm{~b}$ ). At stage III, the potential undergoes $\sim 3 \mathrm{~h}$ equilibrium back to the stable potential. For comparison, the potential response of the $\mathrm{Ag} / \mathrm{AgCl}$ electrode reaches equilibrium quickly (blue line, Figure $2 \mathrm{~b}$ ). Furthermore, the medium-term stability ( $24 \mathrm{~h}$ ) was examined (Figure $2 \mathrm{c}$ ). The potential drift of the $\mathrm{Ag} / \mathrm{AgCl}$ electrode was only $33 \mu \mathrm{Vh}^{-1}$, while the ISM electrode was $114 \mu \mathrm{Vh}^{-1}$. In addition, the long-term stability of the $\mathrm{Ag} / \mathrm{AgCl}$ electrode was tested by placing the electrode in the ambient conditions for one month and soaking it in water and $\mathrm{KCl}$ solution for one week, respectively. As shown in Figure 2d, the calibration curves of the treated electrodes are nearly overlapped within the range of linear response concentration.

The gas and light interferences were finally examined. According to Figure 2e, both electrodes are almost unaffected by light. However, the gases (such as $\mathrm{O}_{2}$ and $\mathrm{CO}_{2}$ ) cause potential fluctuations for the ISM electrode due to a water-layer formation at the SC/ISM interface (Figure 2f). In the water layer, the $\mathrm{O}_{2}$ forms a half-battery, and $\mathrm{CO}_{2}$ changes the $\mathrm{pH}$, leading to significant potential drift, which was also demonstrated by the water-layer tests (Figure 2b). In contrast, the ISM-free $\mathrm{Ag} / \mathrm{AgCl}$ shows nearly no interference from gas. Overall, we demonstrate that the stability of the $\mathrm{Ag} / \mathrm{AgCl}$ electrode is significantly improved compared with the ISM electrode.

\subsection{Ag/AgX-Based SC-ISEs for Various Anion Sensing}

The above results demonstrated that the ISM-free $\mathrm{Ag} / \mathrm{AgCl}$ has a Nernst response, high selectivity, good stability, and reproducibility. This result inspires us to develop 
other $\mathrm{Ag} / \mathrm{AgX}$-based, anion-selective electrodes. Like the method for preparing $\mathrm{Ag} / \mathrm{AgCl}$ electrodes, the polished silver electrode was placed in the corresponding anionic potassium salt solution, and a constant current was applied for 90 min electrodeposition to obtain the $\mathrm{Ag} / \mathrm{AgX}$ electrodes. Subsequently, the potential responses and their calibration curves were obtained. Moreover, the selectivity was examined by continually adding $0.1 \mathrm{M}$ interference ion solution to $0.1 \mathrm{M}$ target ion solution. All measurement results are shown in Figure 3 (insets show the calibration curves). The potential responses of $\mathrm{Ag} / \mathrm{AgBr}$ (Figure 3a) and $\mathrm{Ag} / \mathrm{AgI}$ (Figure 3b) electrodes with the same valence as $\mathrm{Cl}^{-}$are close to the Nernst response, with slopes of $-59.6 \mathrm{mV} \mathrm{dec}^{-1}$ and $-64.7 \mathrm{mV} \mathrm{dec}^{-1}$, and the LODs are $10^{-5.82} \mathrm{M}$ and $10^{-4.61} \mathrm{M}$, respectively.
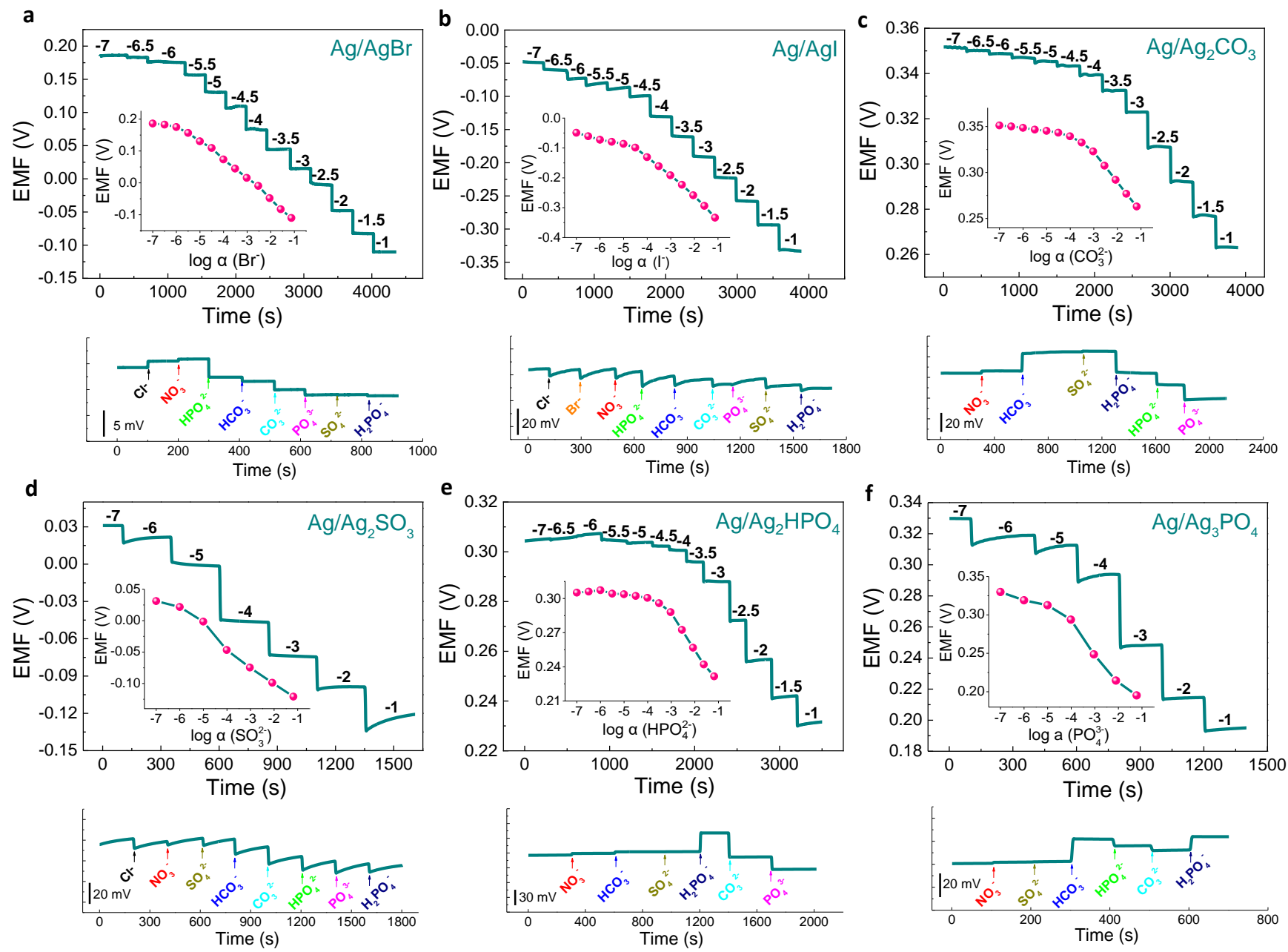

Figure 3. ISM-free $\mathrm{Ag} / \mathrm{AgX}$-based SC-ISEs for anion sensing. Potentiometric response curves toward various valence-state anions from $0.1 \mu \mathrm{M}$ to $0.1 \mathrm{M}$ : (a) $\mathrm{Ag} / \mathrm{AgBr}$ electrode for $\mathrm{Br}^{-}$, (b) $\mathrm{Ag} / \mathrm{AgI}$ electrode for I- , (c) $\mathrm{Ag} / \mathrm{Ag}_{2} \mathrm{CO}_{3}$ electrode for $\mathrm{CO}_{3}{ }^{2-}$, (d) $\mathrm{Ag} / \mathrm{Ag}_{2} \mathrm{SO}_{3}$ for $\mathrm{SO}_{3}{ }^{2-}$, (e) $\mathrm{Ag} / \mathrm{Ag}_{2} \mathrm{HPO}_{4}$ for $\mathrm{HPO}_{4}{ }^{2-}$, and (f) $\mathrm{Ag} / \mathrm{Ag}_{3} \mathrm{PO}_{4}$ electrode for $\mathrm{PO}_{4}{ }^{3-}$. All the insets shown in the figures represent corresponding calibration curves. Interference tests are shown under the response curves.

It is worth noting that their potentials were basically stable and unaffected when other anion interferences were added. Similarly, the potential responses of other divalent anions, such as the $\mathrm{Ag} / \mathrm{Ag}_{2} \mathrm{CO}_{3}$ electrode (Figure 3c), $\mathrm{Ag} / \mathrm{Ag}_{2} \mathrm{SO}_{3}$ electrode (Figure 3d), and $\mathrm{Ag} / \mathrm{Ag}_{2} \mathrm{HPO}_{4}$ electrode (Figure 3e) to their respective anions, were basically consistent with Nernst responses, and their detection limits can also reach a relatively low concentration. For the trivalent anion, the $\mathrm{Ag} / \mathrm{Ag}_{3} \mathrm{PO}_{4}$ electrode exhibits a slope of $-35.6 \mathrm{mV} \mathrm{dec}{ }^{-1}$, which is higher than the theoretical value of the Nernst response (Figure 3f). The possible reason is that the trivalent $\mathrm{PO}_{4}{ }^{3-}$ can be hydrolyzed, resulting in the presence of both 
monovalent and divalent phosphate in the solution. Therefore, the response of $\mathrm{Ag} / \mathrm{Ag}_{3} \mathrm{PO}_{4}$ electrode to trivalent $\mathrm{PO}_{4}{ }^{3-}$ did not fully correspond to the Nernst slope. In the aspect of anti-interference experiment results, the divalent and trivalent $\mathrm{Ag} / \mathrm{AgX}$ electrodes were relatively affected by some anions, which may be mainly due to the hydrolysis between target ions and the co-ion effects. Overall, the above results confirm the feasibility of using insoluble silver salts as solid contact layers to prepare ISM-free anion SC-ISEs.

\subsection{Wearable Sensor for Sweat Analysis}

As the main anion in the extracellular fluid, chloride ion plays an important role in maintaining acid-base balance, osmotic pressure, water-electrolyte distribution, and muscular activity. In the case of excessive sweating, individuals need to supplement electrolytes in time to avoid dehydration due to a large loss of sodium chloride [53]. Therefore, it is of great significance to detect the content of electrolyte salts in the sweat of individuals with involuntary mass perspiration. In addition, chloride ion in sweat is accepted as a biomarker for diagnosis and prognostic tracking of cystic fibrosis [54]. The above various electrochemical characterizations have confirmed that the ISM-free anion-ISEs could be realized by using insoluble silver salts as both functions of SC and ion recognition. All the above electrodes were fabricated on the solid Ag column electrode. Finally, we examined the feasibility of its flexibility and application in a wearable sensor for sweat analysis. As shown in Figure 4a, the flexible $\mathrm{Ag} / \mathrm{AgCl}$ electrode was fabricated in three simple steps. The silver was first sputtered on the PET substrate, and then the surface was chemically oxidized into $\mathrm{AgCl}$ by $\mathrm{FeCl}_{3}$. Finally, the $\mathrm{RM}$ solution was drop-casted on the $\mathrm{Ag} / \mathrm{AgCl}$ as the solid reference electrode (RE), and another bare $\mathrm{Ag} / \mathrm{AgCl}$ was used for the working electrode (WE). The electrode could undergo $120^{\circ}$ bending, which could be satisfied for practical human body test (Figure $4 \mathrm{~b}$ ). On the bending state, the electrode also disclosed Nernstian responses, and the calibration curves were basically coincident (Figure 4c). In addition, since there are some other components in sweat and its $\mathrm{pH}$ value is about $4-8$, the anti-interference ability of the flexible $\mathrm{Ag} / \mathrm{AgCl}$ electrode was further carried out. The experimental results in Figure S2 show that the electrode is free from interferences by other components of sweat. As for the $\mathrm{pH}$ interference, the total potential for the $\mathrm{Ag} / \mathrm{AgCl}$ electrode varies basically within $5 \mathrm{mV}$ upon $\mathrm{pH}$ value changing from 4 to 8 , which is an acceptable fluctuation.

The volunteer ran on a treadmill at a graded load for a period. Figure $4 \mathrm{~d}$ shows the change of $\mathrm{Cl}^{-}$concentration in human sweat measured by the wearable $\mathrm{Ag} / \mathrm{AgCl}$ electrode. When the potential was basically stable within a range, the average concentration of $\mathrm{Cl}^{-}$was about $80 \mathrm{mM}$ (Figure $4 \mathrm{~d}$ ), which is consistent within the concentration of sweat $\mathrm{Cl}^{-}(\sim 10-100 \mathrm{mM})$. During the stage of cooling down, the concentration of $\mathrm{Cl}^{-}$increases gradually due to the evaporation of sweat (Figure 4d). After cooling down, the sweat sample was collected and analyzed by the ion chromatograph. The result demonstrates that the wearable $\mathrm{Ag} / \mathrm{AgCl}$ electrode has a high accuracy for the determination of $\mathrm{Cl}^{-}$ concentration in human sweat with a relative error of $4 \%$ (Figure $4 \mathrm{e}$ ). The calibration process of the wearable $\mathrm{Ag} / \mathrm{AgCl}$ electrode was performed immediately after sweat measurement. The corresponding potential response and calibration curves nearly overlapped (Figures $4 \mathrm{f}$ and S3). It was demonstrated that the wearable $\mathrm{Ag} / \mathrm{AgCl}$ electrode was stable even if it was soaked in sweat. This is a crucial indicator, indicating that the data analyzed in real-time by the electrodes can be considered reasonably accurate, regardless of the wearing individual. In the future, the $\mathrm{Ag} / \mathrm{AgCl}$ electrode can be integrated with other ISM-free SC-ISEs for analyzing other ions, such as $\mathrm{Na}^{+}, \mathrm{K}^{+}$, which can be used for simultaneous and real-time detection of multiple ions in human sweat. 


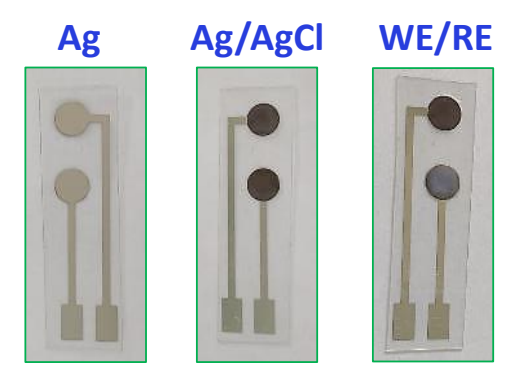

b

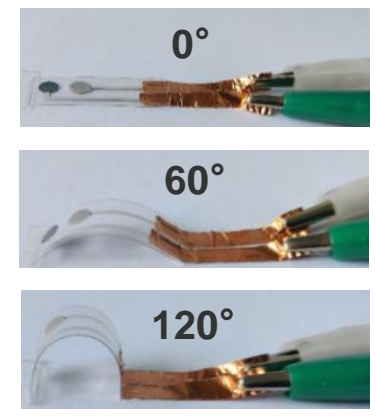

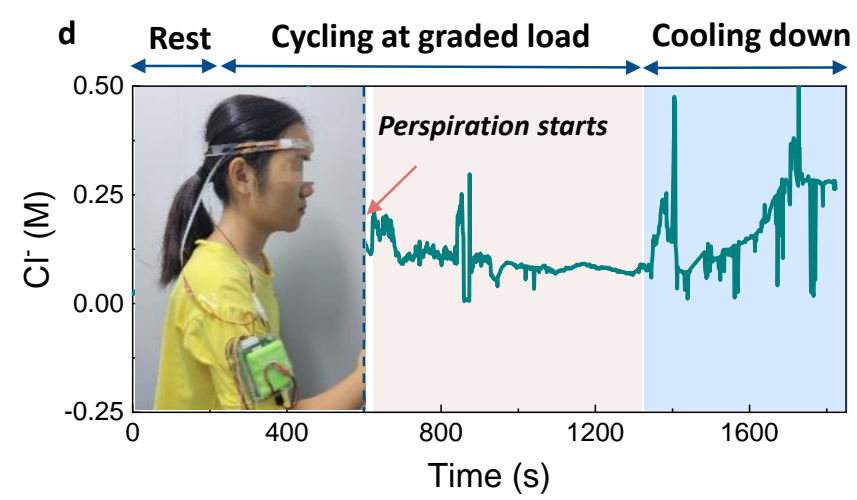

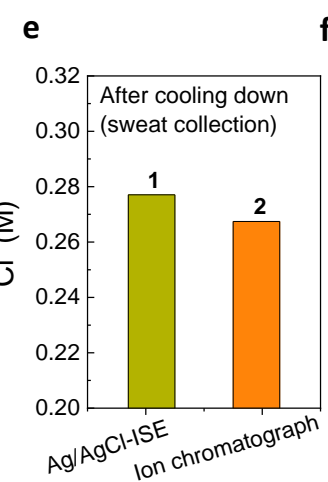

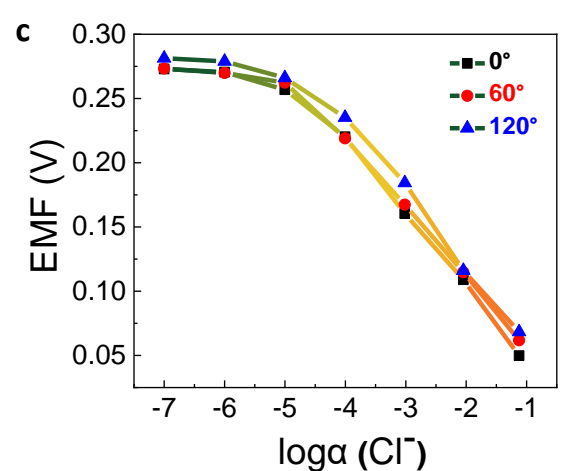

f

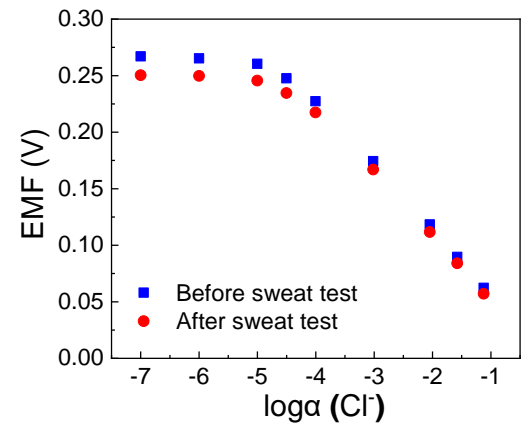

Figure 4. Flexible $\mathrm{Ag} / \mathrm{AgCl}$ electrode toward on-body analysis of $\mathrm{Cl}^{-}$. (a) Optical images of the preparation of flexible $\mathrm{Ag} / \mathrm{AgCl}$ electrode. The working electrode $(\mathrm{WE})$ is $\mathrm{Ag} / \mathrm{AgCl}$, and the reference electrode (RE) is solid $\mathrm{Ag} / \mathrm{AgCl} / \mathrm{PVC}-\mathrm{KCl}$. (b) Optical images of flexible $\mathrm{Ag} / \mathrm{AgCl}$ electrode under different bending angles. (c) Calibration curves of flexible $\mathrm{Ag} / \mathrm{AgCl}$ electrode at different bending angles. (d) In situ monitoring curve of sweat $\mathrm{Cl}^{-}$. A volunteer wearing the prepared wearable $\mathrm{Cl}^{-}$sensor during running. (e) A comparison of ex situ sweat $\mathrm{Cl}^{-}$detection by ion chromatograph. The sweat was collected after cooling down and diluted for the measurements. (f) Calibration curves of flexible $\mathrm{Ag} / \mathrm{AgCl}$ electrode before and after sweat test.

State-of-the-art polymer ISM-based SC-ISEs have been widely used for ion detection in many complex environments. However, the ISM faces a few challenges in many aspects, for example, the biocompatibility of ISM components, water layer effect, and low mechanical strength [5]. Recently, we have proposed an ISM-free concept for SC-ISE based on lithiumion battery materials [49]. In addition to these materials, biocompatible, redox-active polymers based on carbon nanotubes and covalent functionalized organic matrices exhibit the ion-to-electron transduction ability, and ion recognition could have the potential to construct ISM-free ion sensors [55-57].

\section{Conclusions}

Anion sensing has been a long-lasting challenge in solid ion recognition chemistry. This work re-emphasized the classic silver/silver insoluble salts electrodes for constructing ISM-free SC-ISEs. The results were beyond traditional ISM-based SC-ISEs. It exhibited comparable Nernst slope, selectivity, and LOD. The response time, potential stability, and anti-interference ability are superior to the electrode with ISM. Of importance is that this ISM-free electrode has been expanded to other single and multi-valence anions to overcome the lack of anion ionophores in traditional ISM-based SC-ISEs. Finally, the ISM-free electrode exhibited good flexibility and was successfully applied to the on-body analysis of $\mathrm{Cl}^{-}$concentration in human sweat. In the future, these ISM-free anion electrodes can be explored in more complex environments, such as marine ion sensing.

Supplementary Materials: The following are available online at https:/ /www.mdpi.com/article/10 $.3390 /$ membranes11120959/s1. Figure S1: Selectivity coefficient testing of the prepared $\mathrm{Cl}^{-}-\mathrm{ISEs}_{\text {: }}$ potentiometric responses of the $\mathrm{Ag} / \mathrm{AgCl}$ electrode (blue line) and the ISM electrode (orange line) in aqueous solution from $0.1 \mu \mathrm{M}$ to $0.1 \mathrm{M}$ : (a) $\mathrm{KHCO}_{3}$, (b) $\mathrm{KH}_{2} \mathrm{PO}_{4}$, (c) $\mathrm{K}_{2} \mathrm{HPO}_{4}$, (d) $\mathrm{K}_{2} \mathrm{CO}_{3}$, (e) $\mathrm{K}_{2} \mathrm{SO}_{4}$, 
and (f) $\mathrm{K}_{3} \mathrm{PO}_{4}$. Figure S2: $\mathrm{pH}(\mathrm{a})$ and metabolite (b) interference tests of the prepared flexible $\mathrm{Ag} / \mathrm{AgCl}$ electrode. Figure S3: Potential response curves of the flexible $\mathrm{Ag} / \mathrm{AgCl}$ electrode before (black line) and after (red line) sweat test. Table S1: Comparison of Ag/ $\mathrm{AgCl}$-based $\mathrm{Cl}^{-}$sensors with previously reported sensors, Table S2: A comparison of $\mathrm{Cl}^{-}$sensors between $\mathrm{Ag} / \mathrm{AgCl}$ and ISM-based SC-ISEs of $\mathrm{Cl}^{-}$. References [30,38,45,46,58-67] have been cited in Supplementary Materials.

Author Contributions: Conceptualization, S.G.; methodology, C.L.; validation, C.L., L.Z., Y.T. and Z.S.; formal analysis, C.L., K.L., L.X. and Y.L.; resources, Y.H., Y.M. and Y.B.; software, D.H., Y.H., Y.M. and Y.B.; investigation, C.L.; writing-original draft preparation, C.L.; writing-review and editing, S.G.; visualization, D.H.; supervision, S.G.; project administration, L.N. All authors have read and agreed to the published version of the manuscript.

Funding: This research was funded by the National Natural Science Foundation of China (21974032, 21974031, 21974033, 21805052, 21627809 and U2006208), the Science and Technology Research Project of Guangzhou (202102020622), and the Department of Science and Technology of Guangdong Province (2019B010933001).

Institutional Review Board Statement: Not Applicable.

Informed Consent Statement: The informed signed consent was obtained from the volunteer engaging in the activity of this study.

Data Availability Statement: The data are available upon reasonable request from the corresponding author.

Conflicts of Interest: The authors declare no conflict of interest.

\section{References}

1. Bakker, E.; Pretsch, E. The New Wave of Ion-Selective Electrodes. Anal. Chem. 2002, 74, 420A-426A. [CrossRef]

2. Samec, Z. Electrochemistry at the interface between two immiscible electrolyte solutions. Pure Appl. Chem. 2004, 76, $2147-2180$. [CrossRef]

3. Bakker, E.; Pretsch, E. Modern Potentiometry. Angew. Chem. Int. Ed. 2007, 46, 5660-5668. [CrossRef] [PubMed]

4. Bobacka, J.; Ivaska, A.; Lewenstam, A. Potentiometric Ion Sensors. Chem. Rev. 2008, 108, 329-351. [CrossRef]

5. Lyu, Y.; Gan, S.; Bao, Y.; Zhong, L.; Xu, J.; Wang, W.; Liu, Z.; Ma, Y.; Yang, G.; Niu, L. Solid-Contact Ion-Selective Electrodes: Response Mechanisms, Transducer Materials and Wearable Sensors. Membranes 2020, 10, 128. [CrossRef] [PubMed]

6. Shao, Y.; Ying, Y.; Ping, J. Recent advances in solid-contact ion-selective electrodes: Functional materials, transduction mechanisms, and development trends. Chem. Soc. Rev. 2020, 49, 4405-4465. [CrossRef]

7. Zdrachek, E.; Bakker, E. Potentiometric Sensing. Anal. Chem. 2021, 93, 72-102. [CrossRef] [PubMed]

8. Cattrall, R.W.; Freiser, H. Coated wire ion-selective electrodes. Anal. Chem. 1971, 43, 1905-1906. [CrossRef]

9. Liang, R.-N.; Song, D.-A.; Zhang, R.-M.; Qin, W. Potentiometric Sensing of Neutral Species Based on a Uniform-Sized Molecularly Imprinted Polymer as a Receptor. Angew. Chem. Int. Ed. 2010, 49, 2556-2559. [CrossRef] [PubMed]

10. Washe, A.P.; Macho, S.; Crespo, G.A.; Xavier Rius, F. Potentiometric Online Detection of Aromatic Hydrocarbons in Aqueous Phase Using Carbon Nanotube-Based Sensors. Anal. Chem. 2010, 82, 8106-8112. [CrossRef]

11. Ding, J.; Li, B.; Chen, L.; Qin, W. A Three-Dimensional Origami Paper-Based Device for Potentiometric Biosensing. Angew. Chem. Int. Ed. 2016, 55, 13033-13037. [CrossRef] [PubMed]

12. Liang, R.; Ding, J.; Gao, S.; Qin, W. Mussel-Inspired Surface-Imprinted Sensors for Potentiometric Label-Free Detection of Biological Species. Angew. Chem. Int. Ed. 2017, 56, 6833-6837. [CrossRef] [PubMed]

13. Ding, J.; Qin, W. Recent advances in potentiometric biosensors. TrAC-Trends Anal. Chem. 2020, 124, 115803. [CrossRef]

14. Lv, E.; Li, Y.; Ding, J.; Qin, W. Magnetic-Field-Driven Extraction of Bioreceptors into Polymeric Membranes for Label-Free Potentiometric Biosensing. Angew. Chem. Int. Ed. 2021, 60, 2609-2613. [CrossRef] [PubMed]

15. Zelada-Guillen, G.A.; Riu, J.; Duezguen, A.; Rius, F.X. Immediate Detection of Living Bacteria at Ultralow Concentrations Using a Carbon Nanotube Based Potentiometric Aptasensor. Angew. Chem. Int. Ed. 2009, 48, 7334-7337. [CrossRef]

16. Zelada-Guillen, G.A.; Bhosale, S.V.; Riu, J.; Xavier Rius, F. Real-Time Potentiometric Detection of Bacteria in Complex Samples. Anal. Chem. 2010, 82, 9254-9260. [CrossRef]

17. De Marco, R.; Veder, J.-P.; Clarke, G.; Nelson, A.; Prince, K.; Pretsch, E.; Bakker, E. Evidence of a water layer in solid-contact polymeric ion sensors. Phys. Chem. Chem. Phys. 2008, 10, 73-76. [CrossRef]

18. Veder, J.-P.; De Marco, R.; Clarke, G.; Jiang, S.P.; Prince, K.; Pretsch, E.; Bakker, E. Water uptake in the hydrophilic poly(3,4ethylenedioxythiophene): Poly (styrene sulfonate) solid-contact of all-solid-state polymeric ion-selective electrodes. Analyst 2011, 136, 3252-3258. [CrossRef]

19. Cheong, Y.H.; Ge, L.; Lisak, G. Highly reproducible solid contact ion selective electrodes: Emerging opportunities for potentiometry-A review. Anal. Chim. Acta 2021, 1162, 338304. [CrossRef]

20. Rousseau, C.R.; Bühlmann, P. Calibration-free potentiometric sensing with solid-contact ion-selective electrodes. TrAC-Trends Anal. Chem. 2021, 140, 116277. [CrossRef] 
21. Veder, J.-P.; De Marco, R.; Clarke, G.; Chester, R.; Nelson, A.; Prince, K.; Pretsch, E.; Bakkert, E. Elimination of undesirable water layers in solid-contact polymeric ion-selective electrodes. Anal. Chem. 2008, 80, 6731-6740. [CrossRef] [PubMed]

22. Zhou, M.; Gan, S.; Cai, B.; Li, F.; Ma, W.; Han, D.; Niu, L. Effective Solid Contact for Ion-Selective Electrodes: Tetrakis(4chlorophenyl)borate (TB ${ }^{-}$) Anions Doped Nanocluster Films. Anal. Chem. 2012, 84, 3480-3483. [CrossRef] [PubMed]

23. Ye, J.; Li, F.; Gan, S.; Jiang, Y.; An, Q.; Zhang, Q.; Niu, L. Using sp(2)-C dominant porous carbon sub-micrometer spheres as solid transducers in ion-selective electrodes. Electrochem. Commun. 2015, 50, 60-63. [CrossRef]

24. Hu, J.; Stein, A.; Buehlmann, P. Rational design of all-solid-state ion-selective electrodes and reference electrodes. TrAC-Trends Anal. Chem. 2016, 76, 102-114. [CrossRef]

25. Guzinski, M.; Jarvis, J.M.; D’Orazio, P.; Izadyar, A.; Pendley, B.D.; Lindner, E. Solid-Contact pH Sensor without $\mathrm{CO}_{2}$ Interference with a Superhydrophobic PEDOT-C 14 as Solid Contact: The Ultimate "Water Layer" Test. Anal. Chem. 2017, 89, 8468-8475. [CrossRef]

26. Joon, N.K.; He, N.; Ruzgas, T.; Bobacka, J.; Lisak, G. PVC-Based Ion-Selective Electrodes with a Silicone Rubber Outer Coating with Improved Analytical Performance. Anal. Chem. 2019, 91, 10524-10531. [CrossRef]

27. Hiiro, K.; Moody, G.J.; Thomas, J.D. A chlorate ion-selective electrode based on a poly (vinyl chloride)-matrix membrane. Talanta 1975, 22, 918-919. [CrossRef]

28. Ito, S.; Baba, K.; Asano, Y.; Takesako, H.; Wada, H. Development of a nitrate ion-selective electrode based on an Urushi matrix membrane and its application to the direct measurement of nitrate-nitrogen in upland soils. Talanta 1996, 43, 1869-1881. [CrossRef]

29. Sjöberg, P.; Bobacka, J.; Lewenstam, A.; Ivaska, A. All-Solid-State Chloride-Selective Electrode Based on Poly(3-octylthiophene) and Tridodecylmethylammonium Chloride. Electroanalysis 1999, 11, 821-824. [CrossRef]

30. Zielińska, R.; Mulik, E.; Michalska, A.; Achmatowicz, S.; Maj-Żurawska, M. All-solid-state planar miniature ion-selective chloride electrode. Anal. Chim. Acta 2002, 451, 243-249. [CrossRef]

31. Michalska, A.; Dumańska, J.; Maksymiuk, K. Lowering the Detection Limit of Ion-Selective Plastic Membrane Electrodes with Conducting Polymer Solid Contact and Conducting Polymer Potentiometric Sensors. Anal. Chem. 2003, 75, 4964-4974. [CrossRef]

32. Paciorek, R.; Van Der Wal, P.D.; De Rooij, N.F.; Maj-Żurawska, M. Optimization of the Composition of Interfaces in Miniature Planar Chloride Electrodes. Electroanalysis 2003, 15, 1314-1318. [CrossRef]

33. Michalska, A.; Maksymiuk, K. Conducting polymer membranes for low activity potentiometric ion sensing. Talanta 2004, 63, 109-117. [CrossRef] [PubMed]

34. Khripoun, G.A.; Volkova, E.A.; Liseenkov, A.V.; Mikhelson, K.N. Nitrate-Selective Solid Contact Electrodes with Poly(3octylthiophene) and Poly(aniline) as Ion-to-Electron Transducers Buffered with Electron-Ion-Exchanging Resin. Electroanalysis 2006, 18, 1322-1328. [CrossRef]

35. Ganjali, M.R.; Naji, L.; Poursaberi, T.; Taghizadeh, M.; Pirelahi, H.; Yousefi, M.; Yeganeh-Faal, A.; Shamsipur, M. Novel sulfate ion-selective polymeric membrane electrode based on a derivative of pyrilium perchlorate. Talanta 2002, 58, 359-366. [CrossRef]

36. Song, F.; Ha, J.; Park, B.; Kwak, T.H.; Kim, I.T.; Nam, H.; Cha, G.S. All-solid-state carbonate-selective electrode based on a molecular tweezer-type neutral carrier with solvent-soluble conducting polymer solid contact. Talanta 2002, 57, 263-270. [CrossRef]

37. Khaled, E.; Hassan, H.N.A.; Girgis, A.; Metelka, R. Construction of novel simple phosphate screen-printed and carbon paste ion-selective electrodes. Talanta 2008, 77, 737-743. [CrossRef]

38. Sjöberg-Eerola, P.; Nylund, J.; Bobacka, J.; Lewenstam, A.; Ivaska, A. Soluble semiconducting poly(3-octylthiophene) as a solid-contact material in all-solid-state chloride sensors. Sens. Actuators B Chem. 2008, 134, 878-886. [CrossRef]

39. Yuan, D.; Anthis, A.H.C.; Afshar, M.G.; Pankratova, N.; Cuartero, M.; Crespo, G.A.; Bakker, E. All-Solid-State Potentiometric Sensors with a Multiwalled Carbon Nanotube Inner Transducing Layer for Anion Detection in Environmental Samples. Anal. Chem. 2015, 87, 8640-8645. [CrossRef] [PubMed]

40. Lisak, G.; Tamaki, T.; Ogawa, T. Dualism of Sensitivity and Selectivity of Porphyrin Dimers in Electroanalysis. Anal. Chem. 2017, 89, 3943-3951. [CrossRef]

41. Atkins, C.P.; Scantlebury, J.D.; Nedwell, P.J.; Blatch, S.P. Monitoring chloride concentrations in hardened cement pastes using ion selective electrodes. Cem. Concr. Res. 1996, 26, 319-324. [CrossRef]

42. Atkins, C.P.; Carter, M.A.; Scantlebury, J.D. Sources of error in using silver/silver chloride electrodes to monitor chloride activity in concrete. Cem. Concr. Res. 2001, 31, 1207-1211. [CrossRef]

43. Cranny, A.; Harris, N.R.; Nie, M.; Wharton, J.A.; Wood, R.J.K.; Stokes, K.R. Screen-printed potentiometric Ag/AgCl chloride sensors: Lifetime performance and their use in soil salt measurements. Sens. Actuators A Phys. 2011, 169, 288-294. [CrossRef]

44. Sophocleous, M.; Atkinson, J.K. A review of screen-printed silver/silver chloride (Ag/AgCl) reference electrodes potentially suitable for environmental potentiometric sensors. Sens. Actuators A Phys. 2017, 267, 106-120. [CrossRef]

45. Dam, V.A.T.; Zevenbergen, M.A.G.; Schaijk, R. van. Toward wearable patch for sweat analysis. Sens. Actuators B Chem. 2016, 236, 834-838. [CrossRef]

46. Choi, D.H.; Li, Y.; Cutting, G.R.; Searson, P.C. A wearable potentiometric sensor with integrated salt bridge for sweat chloride measurement. Sens. Actuators B Chem. 2017, 250, 673-678. [CrossRef]

47. Zhang, L.; Xu, T.; Ji, W.; Wang, X.; Cheng, S.; Zhang, S.; Zhang, Y.; Zhang, M. Ag 2 S/Ag Nanoparticle Microelectrodes for In Vivo Potentiometric Measurement of Hydrogen Sulfide Dynamics in the Rat Brain. Anal. Chem. 2021, 93, 7063-7070. [CrossRef] 
48. Wu, R.; Chen, X.; Tao, C.; Huang, Y.; Ye, Y.; Wang, Q.; Zhou, Y.; Jin, Q.; Cai, W. An All-Solid-State Silicate Ion-Selective Electrode Using $\mathrm{PbSiO}_{3}$ as a Sensitive Membrane. Sensors 2019, 19, 525. [CrossRef]

49. Lyu, Y.; Zhang, Y.; Xu, L.; Zhong, L.; Sun, Z.; Ma, Y.; Bao, Y.; Gan, S.; Niu, L. Solid-Contact Ion Sensing Without Using an Ion-Selective Membrane through Classic Li-Ion Battery Materials. Anal. Chem. 2021, 93, 7588-7595. [CrossRef]

50. Lewenstam, A.; Blaz, T.; Migdalski, J. All-Solid-State Reference Electrode with Heterogeneous Membrane. Anal. Chem. 2017, 89, 1068-1072. [CrossRef]

51. Xu, J.; Zhang, Z.; Gan, S.; Gao, H.; Kong, H.; Song, Z.; Ge, X.; Bao, Y.; Niu, L. Highly Stretchable Fiber-Based Potentiometric Ion Sensors for Multichannel Real-Time Analysis of Human Sweat. ACS Sens. 2020, 5, 2834-2842. [CrossRef]

52. Gupta, V.K.; Goyal, R.N.; Sharma, R.A. Chloride selective potentiometric sensor based on a newly synthesized hydrogen bonding anion receptor. Electrochim. Acta 2009, 54, 4216-4222. [CrossRef]

53. Lim, T.; Kim, Y.; Jeong, S.M.; Kim, C.H.; Kim, S.M.; Park, S.Y.; Yoon, M.H.; Ju, S. Human sweat monitoring using polymer-based fiber. Sci. Rep. 2019, 9, 17294. [CrossRef]

54. Choi, D.H.; Thaxton, A.; Jeong, I.C.; Kim, K.; Sosnay, P.R.; Cutting, G.R.; Searson, P.C. Sweat test for cystic fibrosis: Wearable sweat sensor vs. standard laboratory test. J. Cyst. Fibros. 2018, 17, e35-e38. [CrossRef]

55. N’Diaye, J.; Bagchi, R.; Howe, J.Y.; Lian, K. Redox Active Organic-Carbon Composites for Capacitive Electrodes: A Review. Sustain. Chem. 2021, 2, 407-440. [CrossRef]

56. Arlyapov, V.A.; Kharkova, A.S.; Kurbanaliyeva, S.K.; Kuznetsova, L.S.; Machulin, A.V.; Tarasov, S.E.; Melnikov, P.V.; Ponamoreva, O.N.; Alferov, V.A.; Reshetilov, A.N. Use of biocompatible redox-active polymers based on carbon nanotubes and modified organic matrices for development of a highly sensitive BOD biosensor. Enzyme Microb. Technol. 2021, 143, 109706. [CrossRef] [PubMed]

57. Khan, R.; Nishina, Y. Covalent functionalization of carbon materials with redox-active organic molecules for energy storage. Nanoscale 2021, 13, 36-50. [CrossRef]

58. Angst, U.; Elsener, B.; Larsen, C.K.; Vennesland, Ø. Potentiometric determination of the chloride ion activity in cement based materials. J. Appl. Electrochem. 2009, 40, 561-573. [CrossRef]

59. Cranny, A.; Harris, N.; White, N. Screen Printed Potentiometric Chloride Sensors. Procedia Eng. 2014, 87, 220-223. [CrossRef]

60. Dam, V.A.T.; Zevenbergen, M.A.G.; van Schaijk, R. Flexible Chloride Sensor for Sweat Analysis. Procedia Eng. 2015, 120, 237-240. [CrossRef]

61. Femenias, Y.S.; Angst, U.; Caruso, F.; Elsener, B. Ag/ AgCl ion-selective electrodes in neutral and alkaline environments containing interfering ions. Mater. Struct. 2016, 49, 2637-2651. [CrossRef]

62. Abbas, Y.; Zhu, X.; de Boer, H.L.; Tanvir, N.B.; Olthuis, W.; van der Berg, A. Potentiometric measurement with a Kelvin probe: Con-tactless measurement of chloride ions in aqueous electrolyte. Sens. Actuators B Chem. 2016, 236, 1126-1132. [CrossRef]

63. Xu, G.; Cheng, C.; Yuan, W.; Liu, Z.; Zhu, L.; Li, X.; Lu, Y.; Chen, Z.; Liu, J.; Cui, Z.; et al. Smartphone-based battery-free and flexible electrochemical patch for calcium and chloride ions detections in biofluids. Sens. Actuators B Chem. 2019, 297, 126743. [CrossRef]

64. Tian, Y.; Zhang, P.; Zhao, K.; Du, Z.; Zhao, T. Application of Ag/AgCl Sensor for Chloride Monitoring of Mortar under Dry-Wet Cycles. Sensors 2020, 20, 1394. [CrossRef] [PubMed]

65. Paciorek, R.; Bieganowski, P.; Maj-Żurawska, M. Miniature planar chloride electrodes. Sens. Actuators B Chem. 2005, 108, 840-844. [CrossRef]

66. Sjöberg-Eerola, P.; Bobacka, J.; Lewenstam, A.; Ivaska, A. All-solid-state chloride sensors based on electronically conducting, semiconducting and insulating polymer membranes. Sens. Actuators B Chem 2007, 127, 545-553. [CrossRef]

67. Tseng, S.; Wu, T.; Chou, J.; Liao, Y.; Lai, C.; Chen, J.; Yan, S.; Huang, M.; Tseng, T.; Nien, Y. Research of sensing characteristic and dynamic measurement of graphene oxides modified flexible arrayed $\mathrm{RuO}_{2}$ chlorine ion sensor. Mater. Res. Bull. 2018, 101, 155-161. [CrossRef] 